\title{
Trend of the spread of COVID-19 in Indonesia using the machine learning prophet algorithm
}

\author{
Nur Hayati, Fauziah, Dendi Rizka Poetra, Dede Wandi \\ Department of Information and Communication Technology, University of Nasional, South Jakarta, Indonesia
}

\begin{tabular}{l}
\hline \hline Article Info \\
\hline Article history: \\
Received Apr 13, 2021 \\
Revised Oct 26, 2021 \\
Accepted Nov 1, 2021 \\
\hline
\end{tabular}

Keywords:

COVID-19

Dataset

Machine learning

Prophet algorithm

Trend

\begin{abstract}
Based on information on the BNPB website on 2 September 2020, the positive rate for coronavirus disease (COVID-19) in Indonesia reached $25.25 \%$ on 30 August 2020. This is a big challenge for the Indonesian government to reduce the positivity rate to meet the standards safe accepted by World Health Organization (WHO) is 5\%. To ensure the accuracy of government policies, accurate data predictions are needed. Therefore, the prophet's machine learning algorithm can be used to see trends in the spread of COVID-19 in the next one year. This algorithm has a fairly high level of accuracy because the data contains time variables which are adjusted to the dataset. In several previous research, the dataset was vast uncertain and small. Meanwhile in this research, data was taken from 2 March 2020 to 12 February 2021 on the KawalCOVID19 website. This data is used to predict from 13 February 2021 to 12 February 2022. There are 3 data used; namely data confirmed, recovered and died. Based on the analysis, the confirmed patient was $22.60-42.11 \%$, died amounted to $21.67 \%-39.00 \%$, and recovered by $22.53-41.82 \%$. The prediction percentage that the average cases died was $2.43 \%$ every day. The accuracy of data confirmed was $43.97 \%$, died was $72.50 \%$ and recovered was $84.24 \%$.
\end{abstract}

This is an open access article under the CC BY-SA license.

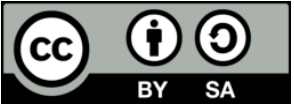

\section{Corresponding Author:}

Nur Hayati

Department of Information and Communication Technology

University of Nasional

Sawo Manila St. No. 61 Pejaten Pasar Minggu, South Jakarta, Indonesia

Email: nurh4y@gmail.com

\section{INTRODUCTION}

Coronavirus disease (COVID-19) is an outbreak that is currently in an uproar throughout the world, including Indonesia. Based on information on the BNPB website 2 September 2020, the positive rate for COVID-19 in Indonesia reached $25.25 \%$ on 30 August 2020 [1]. This is a big challenge for the Indonesian government to reduce the positivity rate to meet the standards safe accepted by world health organization (WHO) is 5\% [1]. There are 4 categories of regional colors [2]; namely the green zone, an area where there are no cases of coronavirus infections. The public is allowed to carry out activities as usual while still following health protocols. Second, the yellow zone means there have been several cases of COVID-19 with some local transmission. This is where the large-scale social restrictions (PSBB) are carried out partially. Third, the red zone means that there are still cases of COVID-19 in one or more clusters with a high increase in cases. In this zone, serious health protocols are needed such as closing schools and places of workship. Fourth, the black zone where cases of COVID-19 in an area have been so severe that they have reached over 2000s. The spread of COVID-19 is usually through droplets from coughs or sneezes produced from an infected person. Many of the infections that come are caused by direct contact with someone infected. The 
incubation period for infection ranges from one to fourteen days. However, sometimes the disease caused by COVID-19 can spread without severe symptoms. Several studies have been conducted in the analysis of COVID-19 [3]-[8]. There has been an increase in patients identified as COVID-19 [9]-[11].

In research using deep learning methods in the form of classification and long short-term memory (LSTM) has given a prominent value of mean squared error (MSE) and root mean square error (RMSE) as 1,034 and 1,002 respectively [12]. Whereas the results of lockdown analysis in Italy, China, and France using the autoregressive integrated moving average (ARIMA) model resulted in a decrease in confirmed patients and an increase in patients who recovered from COVID-19 [13], [14] and for Indonesia, it resulted in an Rsquared error of 0.9793 with the neural network method [15] and to enlarge the efficiency of the algorithm, it is important to estimate the number of hidden layers and their chronological order [16]. Other results suggest statistical analysis, modeling, and artificial intelligence contain the spread of COVID-19 and highlight the impact in the coming days [17]-[19].

To get the spread of COVID-19 for the next period, can use the prophet machine learning algorithm, where the prophet algorithm works with time-series data that is claimed to have a fairly high level of prediction accuracy [20]. This prophet algorithm only requires two values in one data frame table, namely a column containing the time/date/day and a column containing a value that we will predict [20]. This algorithm is considered accurate because the data contains time variables adjusted to the dataset [21]-[23]. In the previous analysis with prophet algorithm, the dataset was from several online portals that announced public information about COVID-19 in Indonesia that was taken in 1 day on 7 October 2020 [24]. Meanwhile, in this study, data was taken for 1 years. The use of the original data are more numerous and diverse than previous research which included data on weekdays and holidays is expected to improve the accuracy of the model prophet. This study will predict a positive number of confirmed, recovered, and died for the next year.

\section{COVID-19 DATASET}

The dataset used comes from KawalCOVID19 website. The data was taken from 2 March 2020 to 12 February 2021. The data obtained were in the form of daily cases of positive covid patients. Then, the data is made into dataset as show in Table 1. Based on the Table 1, the number of data sets used in this study was 347. The data consisted of confirmed, recovered, and death from covid patients. We can see that there is increase data of confirmed, death and recovered in every day.

Table 1. Dataset of confirmed, death, and recovered of COVID-19 [25]

\begin{tabular}{ccccc}
\hline Observation & Date & Confirmed & Deaths & Recovered \\
\hline 0 & March 02, 2020 & 2 & 0 & 0 \\
1 & March 03, 2020 & 2 & 0 & 0 \\
2 & March 04, 2020 & 2 & 0 & 0 \\
3 & March 05, 2020 & 2 & 0 & 0 \\
4 & March 06, 2020 & 4 & 0 & 0 \\
$\ldots$ & $\ldots$ & $\ldots$ & $\ldots$ & $\ldots$ \\
345 & February 11, 2021 & $1,191,990$ & 32,381 & 993,117 \\
346 & February 12, 2021 & $1,201,859$ & 32,656 & $1,004.117$ \\
\hline
\end{tabular}

\section{SPREAD OF COVID-19}

Based on the data obtained, the spread of COVID-19 in Indonesia has increased every month. In Figure 1, we can see that the number of confirmed COVID-19 patients increases every month. By the number confirmed affected by COVID-19, most of them recovered from COVID-19. Although it appears that the number of deaths is less than the number recovered, this virus can still cause fatal things, namely death. Table 2 shows the addition of daily cases for the last month. In the Table 2, we can see that $86.8 \%$ of patients were recovered from COVID-19, and as many as $2.25 \%$ were died. In the timeframe from March 2020 to February 2021, data on the addition of the highest daily cases during the last month were obtained. In Table 3, we can see that the highest patient data in the last month was on 30 January 2021, amounting to 14,158 patients affected by COVID-19.

Table 2 . The average daily cases additions over the last month (12 January 2021 to 12 February 2021)

\begin{tabular}{lc}
\hline \multicolumn{1}{c}{ Cases } & Number of Cases \\
\hline Confirmed & 11,454 \\
Deaths & 258 \\
Recovered & 9,945 \\
\hline
\end{tabular}


Table 3. The highest increase in daily cases during the last month (12 January 2021 to 12 February 2021)

\begin{tabular}{cl}
\hline \multicolumn{1}{c}{ Prediction } & \multicolumn{1}{c}{ Number of Cases } \\
\hline 30 January 2021 & 14,158 (Confirmed) \\
28 January 2021 & 476 (Deaths) \\
8 February 2021 & 13,038 (Recovered) \\
\hline
\end{tabular}

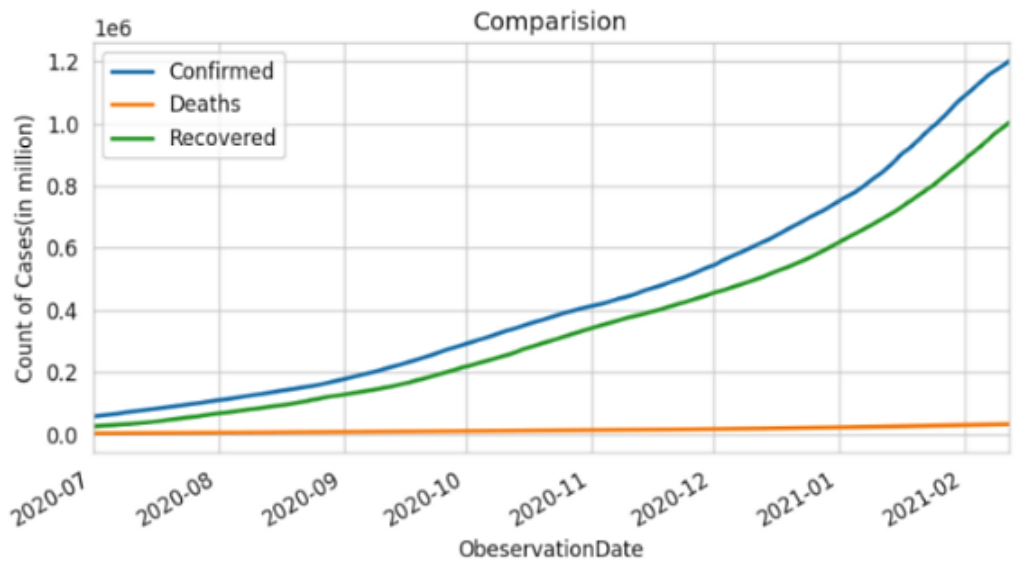

Figure 1. Visualization of case from 1 March 2020 until 12 February 2021

\section{PROPHET ALGORITHM MODEL}

Prophet is a procedure for predicting time series data based on an additive model in which nonlinear trends match data on annual, weekly, daily, seasonal, and holiday effects. The prophet's algorithm fits many linear and nonlinear functions of time as a component (time as regressor). Forecasting FB prophet works best with time series that have seasonal effects (strong seasonal effects and some historical season data). FB Prophet is strong at data loss and trend shifts, and usually handles outliers well. The simple functions of the prophet [26] algorithm is (1).

$$
k(t)=\operatorname{tr}(t)+s e(t)+h o(t)+i d(t)
$$

Where:

$\operatorname{tr}(t)=$ trend

$\operatorname{se}(t)=$ seasonality

ho $(t)=$ holiday

$\operatorname{id}(t)=$ individual

Figure 2 is a visualization of the training data and test data.

Because there were too many ready-made datasets and this step was carried out only to ensure the accuracy of the model, it was decided to take only the last 3 months of data from 11 November 2020 to 18 January 2021 for train data and 19 January 2021 to 12 February 2021 for test data. There is a difference of 25 days between the train data and the test data, from this gap the model will be set to predict for the next 25 days with the train data input. After inputting the train data, the model already has predictions for the next 25 days. If the model of prediction (blue line) is below from the real data (red line), then the model can be used to determine predictions of the next spread of COVID-19. In Figure 2, it can be seen that the prediction model of confirmed, died, and recovered are below the real data so that it can be used to predictions the spread of COVID-19.

The level of accuracy is needed to see how valid the prediction model we get from the original data. The greater the value of accuracy, the more valid the prediction model that has been obtained. The following is a formula for determining the accuracy value:

$$
\begin{aligned}
R-\text { squared } & =1-\frac{\text { first sum of error }}{\text { second sum of error }} \\
& =\frac{\text { the amount of predicted correct training data }}{\text { the total amount of predicted data }}
\end{aligned}
$$




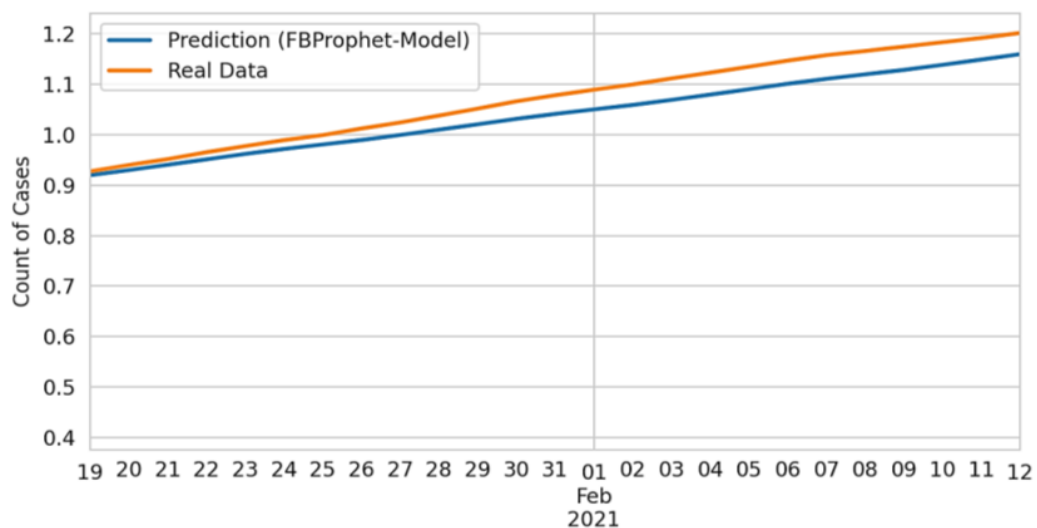

(a)

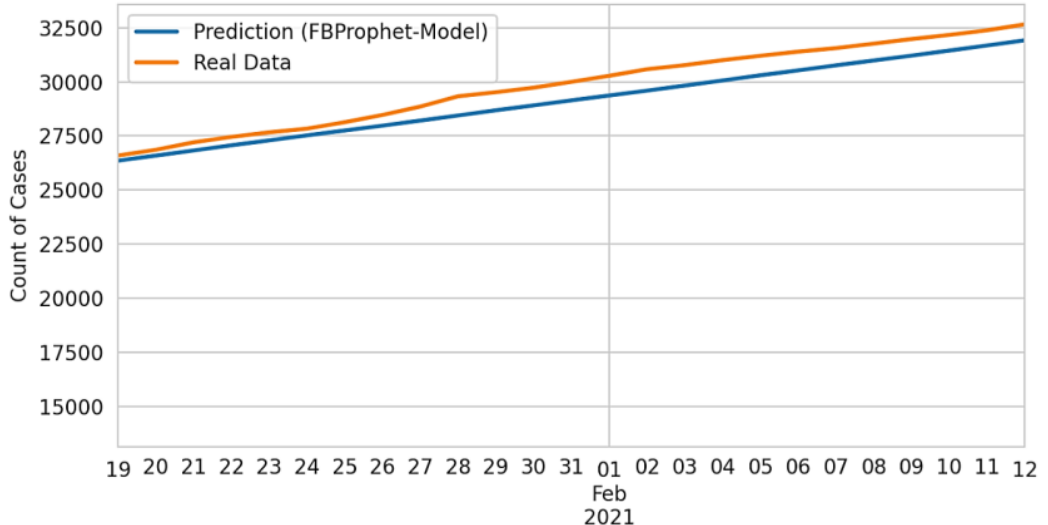

(b)

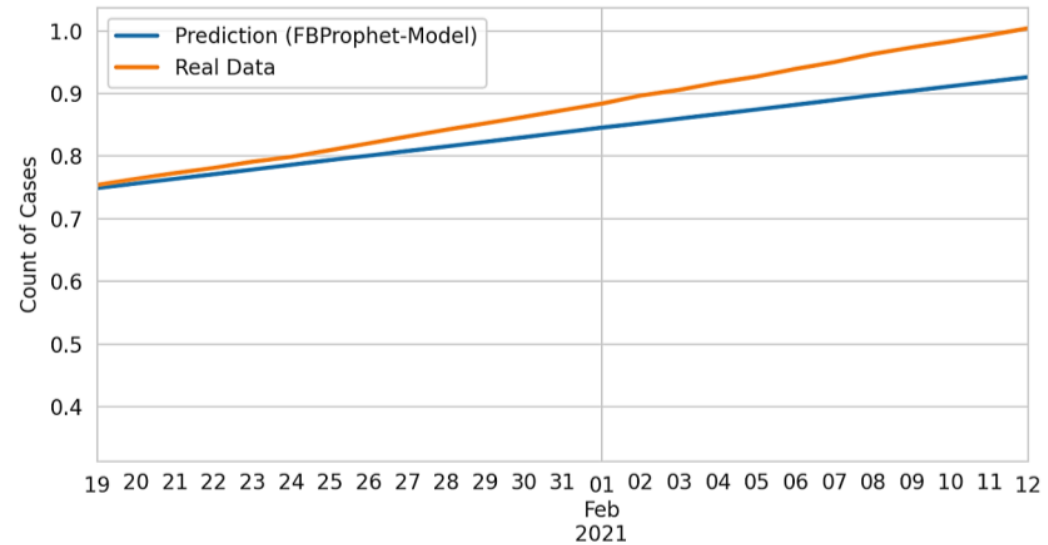

(c)

Figure 2. Prediction model versus: (a) real data (test data) of confirmed cases, (b) deaths cases, and (c) recovered cases

\section{RESULTS AND DISCUSSION}

This research uses Google Colab with python programming language. In this research, a forecasting was carried out for the next 1 year of data starting from 13 February 2021 to 12 February 2022. There are 3 data that will be predicted (according to the dataset in the original data), namely confirmed data, recovered and died. The following is the prediction data for 1 year.

In Table 4 we can see that the prediction for the spread of COVID-19 will increased in every day. From dataset prediction we can predicted the percentage of three months as following Table 5. Based on Table 5, the percentage of three months for confirmed patients was $22.60-42.11 \%$, died was $21.67-39.00 \%$, and recovered was $22.53-41.82 \%$. Furthermore, to predict the average addition of daily cases can be seen in 
the following Table 6 . In Table 6, we can see that the predicted percentage of the average cases dying is $2.43 \%$, and cases recovered by $80.71 \%$ for each day. Furthermore, we can see the prediction of the highest increase in daily cases in the Table 7.

Table 4. The prediction data of confirmed, death and recover for 1 year

\begin{tabular}{ccccc}
\hline Observation & Date & Confirmed & Deaths & Recovered \\
\hline 347 & 13 February 2021 & $1,172,774$ & 32,350 & 957,141 \\
348 & 14 February 2021 & $1,181,827$ & 32,571 & 964,447 \\
349 & 15 February 2021 & $1,190,880$ & 32,791 & 971,753 \\
350 & 16 February 2021 & $1,199,933$ & 33,011 & 979,059 \\
351 & 17 February 2021 & $1,208,985$ & 33,231 & 986,365 \\
$\ldots$ & $\ldots$ & $\ldots$ & $\ldots$ & $\ldots$ \\
710 & 11 February 2022 & $4,458,961$ & 112,316 & $3,609,237$ \\
711 & 12 February 2022 & $4,468,014$ & 112,536 & $3,616,543$ \\
\hline
\end{tabular}

Table 5. The prediction results for the total confirmed cases (13 February 2021 to 12 February 2022)

\begin{tabular}{lccc}
\hline \multicolumn{1}{c}{ Date } & Confirmed & Deaths & Recovered \\
\hline 13 May 2021 & $1,978,724$ & 51,969 & $1,607,848$ \\
13 August 2021 & $2,811,990$ & 72,237 & $2,280,201$ \\
13 November 2021 & $3,644,385$ & 92,485 & $2,951,312$ \\
12 February 2022 & $4,468,195$ & 112,531 & $3,616,163$ \\
\hline
\end{tabular}

Table 6 . The prediction result of addition average in daily cases (13 February 2021 to 12 February 2022)

\begin{tabular}{lc}
\hline Prediction & Number of Cases \\
\hline Confirmed & 9,052 \\
Deaths & 220 \\
Recovered & 7,306 \\
\hline
\end{tabular}

Table 7. The prediction result of the highest addition in daily cases

\begin{tabular}{|c|c|c|c|c|c|}
\hline \multicolumn{2}{|l|}{ Confirmed } & \multicolumn{2}{|l|}{ Deaths } & \multicolumn{2}{|l|}{ Recovered } \\
\hline Date & $\begin{array}{l}\text { Predicted } \\
\text { Value }\end{array}$ & Date & $\begin{array}{l}\text { Predicted } \\
\text { Value }\end{array}$ & Date & $\begin{array}{l}\text { Predicted } \\
\text { Value }\end{array}$ \\
\hline 20,27 February 2021 & 9,455 & 19, 26 February 2021 & 232 & 19, 26 February 2021 & 7,552 \\
\hline $3,10,17,24$ April 2021 & & $2,9,16,23,30$ April 2021 & & $2,9,16,23,30$ April 2021 & \\
\hline $1,8,15,22,29$ Мay 2021 & & $7,14,21,28$ May 2021 & & $7,14,21,28$ May 2021 & \\
\hline $5,12,19,26$ June 2021 & & $4,11,18,25$ June 2021 & & $4,11,18,25$ June 2021 & \\
\hline $4,11,18,25$ September 2021 & & $3,10,17,24$ September 2021 & & $3,10,17,24$ September 2021 & \\
\hline $2,9,16,23,30$ October 2021 & & $1,8,15,22,29$ October 2021 & & $1,8,15,22,29$ October 2021 & \\
\hline $6,13,20,27$ November 2021 & & $5,12,19,26$ November 2021 & & $5,12,19,26$ November 2021 & \\
\hline 4, 11, 18, 25 December 2021 & & $3,10,17,24,31$ December 2021 & & $3,10,17,24,31$ December 2021 & \\
\hline 1, 8, 15, 22, 29 January 2022 & & 7, 14, 21, 28 January 2022 & & 7, 14, 21, 28 January 2022 & \\
\hline
\end{tabular}

In Table 7 we can see the prediction of the highest addition of confirmed cases of COVID-19 occurring on Saturdays except 5 March 2021. That means an increase in the number of confirmed COVID19 , died and recovered during holidays which is one of the parameters of the trend on the prophet algorithm. The results of the prediction of the highest daily increase of cases from the 1-year simulation are 9,455 people for confirmed cases, 232 people for dead cases and 7,552 people for recovered cases. For a visualization of the 1-year prediction, we display it in Figure 3.

Based on Figure 3, the black line shows the dataset used as training data, while the blue line is the prediction model of the Prophet algorithm. Because the training data is already on the line of the prediction model, we can use this prediction model for the prediction process for the next 1 year. For blue shading is the lower limit and upper limit of the prediction data data. The longer the prediction time, the bigger of the lower limit and upper limit. After obtaining a prediction model and predictive data for the spread of COVID-19, the authors then compare and calculate the accuracy value of the prediction data for the next 1 year with real data that is currently running from 13 February 2021 to 3 May 2021. Based on the Table 8, it can be seen that the accuracy rate of patients with confirmed COVID-19 is below 50\%, namely 43.97\%. Meanwhile, the accuracy of data recovered and died is above $50 \%$. The higher the level of accuracy obtained, the more accurate the prediction model will be made with the real data. The level of accuracy can be done for the same time span, for example one year starting from the initial prediction data and then comparing it with the original data that is currently running. 


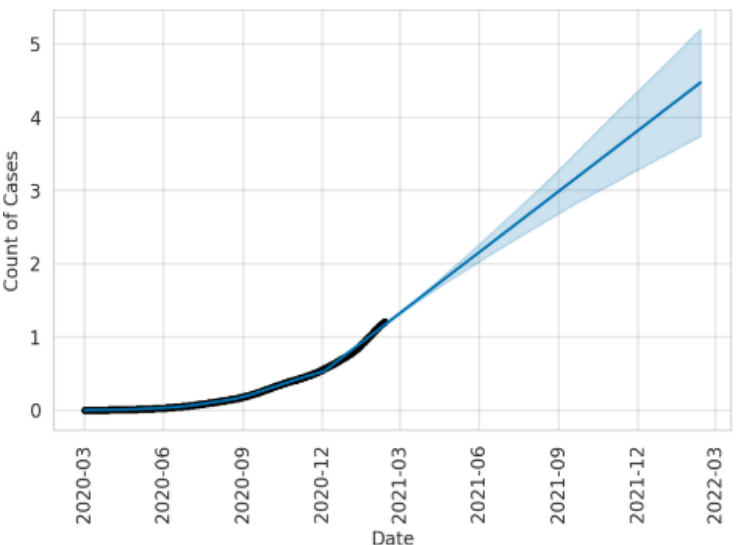

(a)

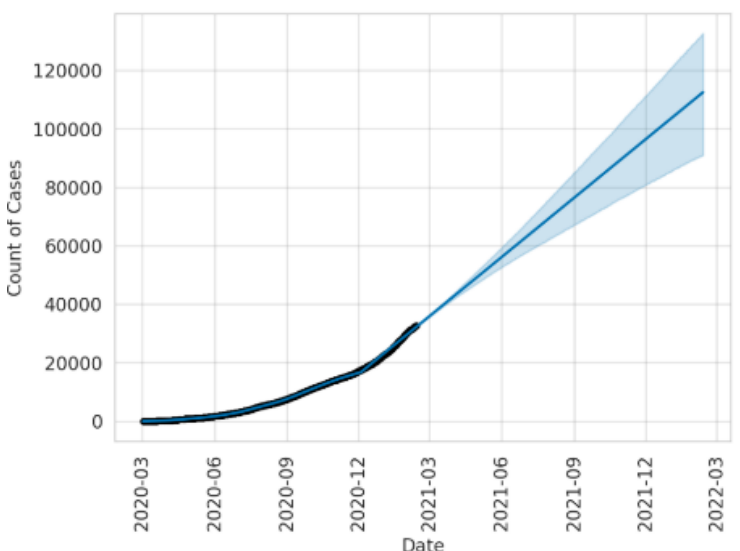

(b)

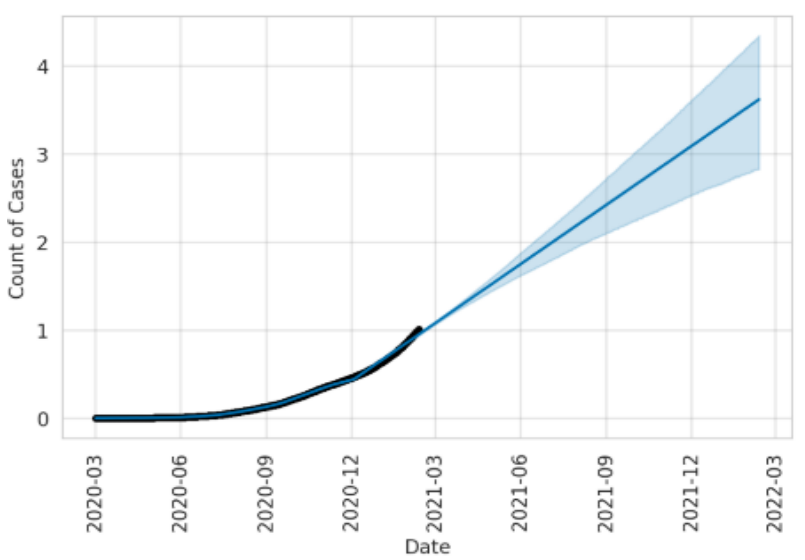

(c)

Figure 3. The Forecast is (a) confirmed cases, (b) deaths cases, and (c) recovered cases for 1 year (12 February 2021-12 February 2022)

Table 8. The accuracy of confirmed, deaths and recover at 13 February 2021 to 3 May 2021

\begin{tabular}{ll}
\hline \multicolumn{1}{c}{ Prediction } & Number of Cases \\
\hline Confirmed & $43.97 \%$ \\
Death & $72.50 \%$ \\
Recovered & $84.24 \%$ \\
\hline
\end{tabular}

\section{RESEARCH METHOD}

Based on Figure 4, the research method is divided into several parts, namely data gathering, data preprocessing, modeling, and evaluation. In the first stage, it begins by taking a dataset from data KawalCOVID19 website. Data gathering starts with taking the main dataset then filtering the main dataset and then creating a new dataset to retrieve the attributes needed by the prediction/forecasting model, after the new dataset has been created, the dataset is ready and the new dataset will be applied to the model. Next, we do data preprocessing with manipulate the filtered dataset before inputting it to the FBProphet model. FBProphet only accepts 2 columns of input, the date column (observation date) must be in the ideal form, namely the data frame and the data type must be datetime64 [ns] then have the YYYY-MM-DD format and the column you want to predict must be numeric. After preprocessing, the dataset is ready to be input into the model. But to ensure the accuracy of the model, we must train the model and test the model with the input dataset and then the results will be compared. Next, comparing the results of the prediction of 25 days with the 25 days original data test. If prediction data is under original data test, it means the model already to prediction for the next one years. After prediction, then calculate the accuracy value from the predicted data. The higher of accuracy value, mean the closer of prediction data to real data. The Figure 4 is a flowchart of the research methodology. 


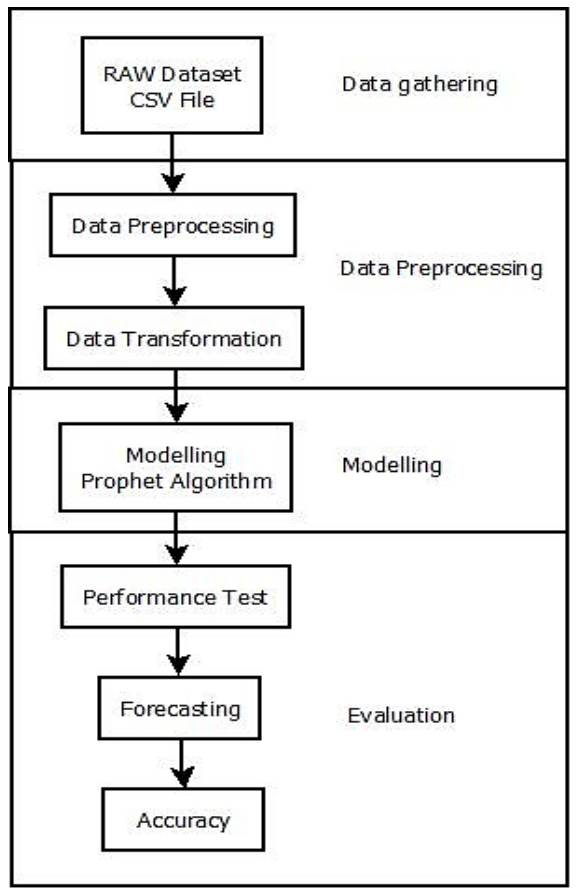

Figure 4. Research methods

\section{CONCLUSION}

To reduce the spread of COVID-19 and make the right decisions for the government, predictions of future cases are needed. Therefore, the prophet algorithm is used to predict the spread of COVID-19 for the next one year. The authors choose prophet algorithm because this algorithm has a fairly high level of accuracy. For the authors, this research was to proof the accuracy of prediction model with a time span of one year (2 March 2020 to 12 February 2021). The percentage for confirmed patients was $22.60-42.11 \%$, died was $21.67-39.00 \%$, and recovered was $22.53-41.82 \%$. The predicted percentage of cases died was $2.43 \%$ every day. Then for the level of accuracy, the author uses the prediction and original data from 13 February 2021 to 3 May 2021. In further research, the level of accuracy was carried out at the same time span as the prediction modeling time. The accuracy of data confirmed was $43.97 \%$, died was $72.50 \%$ and recovered was $84.24 \%$. Based on the results of the accuracy, it seen that data for patients with confirmed covid-19 get a value below $50 \%$, which is different from data on death and recovery which reaches an accuracy rate of more than $50 \%$. This can be due to the modeling process where the prediction model wasn't so close to the model from the original data. This means that the use of the Prophet algorithm to predict the spread of COVID-19 in Indonesia is still not valid enough, so validation or comparison is needed using other logistical algorithms. However, the data on COVID-19 reconfirmation in Indonesia is still very high, so it needs the right decision by the government.

\section{REFERENCES}

[1] Windhu. "Distribution of COVID-19 Health Materials Update 2 September 2020," 2020. Accessed: Mar. $02,2020$. [Online]. Available: bnpb.go.id. https://bnpb.go.id/index.php/infografis/distribusi-alat-material-kesehatan-covid19update-2-september-2020.

[2] "Risk Zonation Map." covid19.go.id. Accessed: Mar. 02, 2020. [Online]. Available: https://www.covid19.go.id/peta-risiko.

[3] L. Jia, K. Li, Y. Jiang, X. Guo, and T. Zhao, "Prediction and Analysis of Coronavirus Disease 2019," PLOS ONE, 2020, doi: 10.1371/journal.pone.0239960.

[4] Q. Li and W. Feng, "Trend and Forecasting of the COVID-19 Outbreak in China," Journal of Infection, vol. 8, no. 4, pp. 469-496, 2020, doi: 10.1016/j.jinf.2020.02.014.

[5] B. Pavlyshenko, "Machine-Learning Models for Sales Time Series Forecasting," Data, vol. 4, no. 1, 2019. doi: 10.3390/data4010015.

[6] J. Kumar and K. P. S. S. Hembram, "Epidemiological Study of Novel Corona Virus (COVID-19)," International Journal of Community Medicine and Public Health, vol. 8, no. 3, pp. 1364-1369, 2020, doi: 10.18203/23946040.ijcmph20210828. 
[7] J. Fattah, L. Ezzine, Z. Aman, H. El Moussami, and A. Lachhab, "Forecasting of demand using ARIMA model," International Journal of Engineering Business Management, 2018, doi:10.1177/1847979018808673.

[8] B. M. Pavlyshenko, "Linear, Machine Learning And Probabilistic Approaches For Time Series Analysis," In 2016 IEEE First International Conference on Data Stream Mining \& Processing (DSMP), 2016, pp. 377-381, doi: 10.1109/DSMP.2016.7583582.

[9] B. Suvarna, T. M. Padmaja, V. Dondeti, H. Telaprolu, and H. Pappula, "Machine Learning Algorithm for Predicting Number of Covid-19 Cases," Journal of Xi'an University of Architecture \& Technology, vol. 12, no. 6, pp. 1176-1186, 2020.

[10] P. Wang, X. Zheng, J. Li, and B. Zhu, "Prediction of epidemic trends in COVID-19 with logistic model and machine learning technics," Chaos, Solitons \& Fractals, vol. 139, 2020, doi: 10.1016/j.chaos.2020.110058.

[11] S. Tuli, S. Tuli, R. Tuli, and S. S. Gill, "Predicting the growth and trend of COVID-19 pandemic using machine learning and cloud computing," Internet of Things, vol. 11, 2020, doi: 10.1016/j.iot.2020.100222.

[12] K. Kumar and D. P. Gandhmal, "An intelligent indian stock market forecasting system using LSTM deep learning," International Journal of Electrical Engineering and Computer Science (IJEECS), vol. 21, no. 2, pp. 1082-1089, 2021, doi: 10.11591/ijeecs.v21.i2.pp1082-1089.

[13] N. Chintalapudi, G. Battineni, and F. Amenta, "Covid-19 Virus Outbreak Forecasting of Registered and Recovered Cases After Sixty Day Lockdown in Italy: A Data Driven Model Approach.," J. Microbiol. Immunol. Infect., vol. 53, no. 3. pp. 396-403, 2020, doi: 10.1016/j.jmii.2020.04.004.

[14] D. Fanelli, and F. Piazza, "Analysis and forecast of COVID-19 spreading in China, Italy and France," Chaos, Solitons \& Fractals, vol. 134, 2020, doi: 10.1016/j.chaos.2020.109761.

[15] Z. E. Rasjid, R. Setiawan, and A. Effendi, "A Comparison: Prediction of Death and Infected COVID-19 Cases in Indonesia Using Time Series Smoothing and LSTM Neural Network," Procedia Computer Science, vol. 179, pp. 982-988, 2021, doi: 10.1016/j.procs.2021.01.102.

[16] D. A. Jasm, M. M. Hamad and A. T. H. Alrawi "Deep image mining for convolution neural network," Indonesian Journal of Electrical Engineering and Computer Science (IJEECS), vol. 21, no. 1, pp. 347-352, 2020, doi: 10.11591/ijeecs.v20.i1.pp347-352.

[17] R. Pal, A. A. Sekh, S. Kar, and D. K. Prasad, "Neural Network Based Country Wise Risk Prediction of COVID19," Applied Sciences, vol. 10, no. 18, 2020, doi: 10.3390/app10186448.

[18] M. H. D. M. Ribeiro, R. G. da Silva, V. C. Mariani, and L. dos S. Coelho., "Short-term forecasting covid-19 cumulative confirmed cases: Perspectives for brazil.," Chaos, Solitons \& Fractals, vol. 135, 2020, doi: 10.1016/j.chaos.2020.109853.

[19] X. Zhang, R. Ma, and L. Wang., "Predicting Turning Point, Duration and Attack Rate of Covid-19 Outbreaks in Major Western Countries," Chaos Solitons \& Fractals, vol. 135. 109829. doi: 10.1016/j.chaos.2020.109829.

[20] "Prophet Forecasting at Scale." https://facebook.github.io/prophet/ (accessed Mar. 02, 2020).

[21] P. N. Mahalle, N. P. Sable, N. P. Mahalle, and G.R. Shinde, "Data Analytics: COVID-19 Prediction Using Multimodal Data," Preprints, 2020, doi: 10.20944/preprints202004.0257.v2.

[22] N. Kumar and S. Susan, "COVID-19 Pandemic Prediction using Time Series Forecasting Models," In 2020 11th International Conference on Computing, Communication and Networking Technologies (ICCCNT), 2020, pp. 1-7, doi: 10.1109/ICCCNT49239.2020.9225319.

[23] K. G. Amit, S. Vijander, M. Priya, and M. T. G. Carlos, "Prediction of Covid-19 Pandemic Measuring Criteria Using Support Vector Machine, Prophet and Linear Regression Models in Indian Scenario," Journal of Interdisciplinary Mathematics, vol. 24, 2021, doi: 10.1080/09720502.2020.1833458.

[24] S. Sreeramula and D. Rahardjo, "Estimating COVID-19 Rt in Real-time: An Indonesia health policy perspective," Machine Learning with Applications, vol. 6, 2021, doi: 10.1016/j.mlwa.2021.100136.

[25] Dataset COVID-19. 12 February 2021. [Online]. Available: https://docs.google.com/spreadsheets/d/ 1ma1T9hWbec1pXlwZ89WakRk-OfVUQZsOCF14FwZxzVw/edit?ts=60263008\#gid=387345074

[26] W. A. Robson, "The Math of Prophet- Breaking Down the Equation Behind Facebook's Open-Source Time Series Forecasting Procedure," Medium, 2019. Accessed: Apr. 02, 2020. Available: https://medium.com/futurevision/the-math-of-prophet-46864fa9c55a.

\section{BIOGRAPHIES OF AUTHORS}

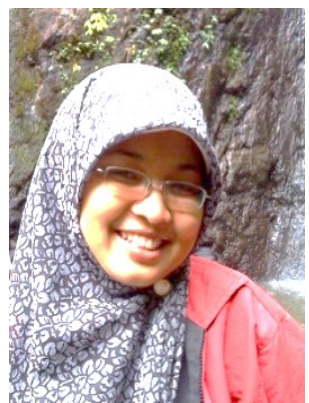

Nur Hayati is a graduate of S1 mathematics at University of Nasional Jakarta, master of magister technology information at University of Indonesia. Lecturer at the department of information and communication technology, University of Nasional, Jakarta. Currently as a head of computer vision and multimedia laboratorium and student doctoral at computer science, mathematics and natural science, Bogor Agricultur Institut. Has received 5 DIKTI grants in the fields of information systems, system security, e-commerce, computational mathematics and received the best international proceedings award at the 2019 ICSCC event. 

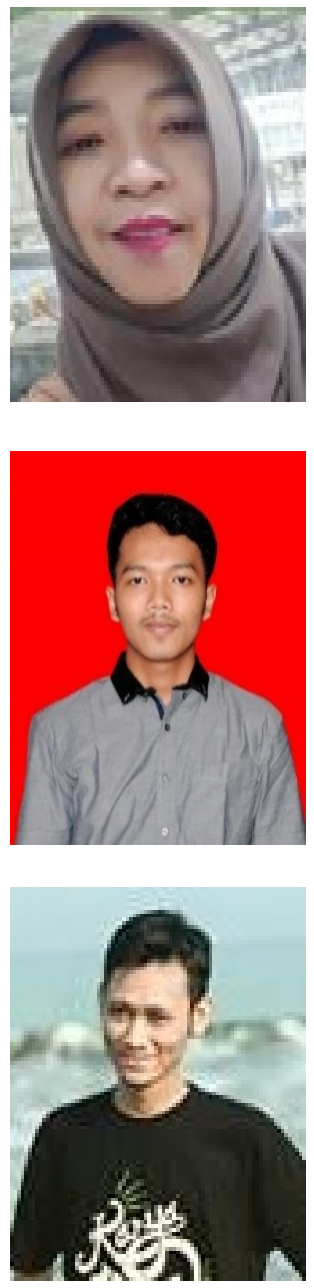

Fauziah is a graduate of S1 information system at University of Gunadarma, Depok, magister management system information at University of Gunadarma, doctoral program information technology at University of Gunadarma. Awarded DIKTI grants of research for 5 years and textbook grants in 2010. As a book author, including books at junior high school, senior high school and college level from 2003 until now. Has award as an outstanding lecturer at the KOPERTIS level of region III Jakarta in 2013 at the third rank.

Dendi Rizka Poetra is a student college at department of information and communication technology majoring informatics at University of Nasional. Currently doing an internship program at PT. NetTo Cyber Indonesia as customer service. Has won the student creativity program at a University od Nasional.

Dede Wandi is a graduate of S1 at department of information and communication technology majoring informatics at University of Nasional, Jakarta. Work as a software engineering at the government company. 